\title{
The role of big five factors on predicting job crafting propensities amongst administrative employees in a South African tertiary institution
}

\begin{tabular}{|c|c|}
\hline \multicolumn{2}{|l|}{$\begin{array}{l}\text { Authors: } \\
\text { Clement Bell }^{1} \\
\text { Noxolo Njoli }{ }^{2}\end{array}$} \\
\hline \multicolumn{2}{|c|}{$\begin{array}{l}\text { Affiliations: } \\
{ }^{1} \text { Department of Industrial } \\
\text { Psychology, University of Fort } \\
\text { Hare, South Africa }\end{array}$} \\
\hline \multicolumn{2}{|c|}{$\begin{array}{l}{ }^{2} \text { Department of Human } \\
\text { Resources, University of Fort } \\
\text { Hare, South Africa }\end{array}$} \\
\hline \multicolumn{2}{|c|}{$\begin{array}{l}\text { Corresponding author: } \\
\text { Clement Bell, } \\
\text { clementbell86@gmail.com }\end{array}$} \\
\hline \multicolumn{2}{|c|}{$\begin{array}{l}\text { Dates: } \\
\text { Received: } 11 \text { Mar. } 2015 \\
\text { Accepted: } 05 \text { Nov. } 2015 \\
\text { Published: } 28 \text { Apr. } 2016\end{array}$} \\
\hline \multicolumn{2}{|c|}{$\begin{array}{l}\text { How to cite this article: } \\
\text { Bell, C., \& Njoli, N. (2016). } \\
\text { The role of big five factors on } \\
\text { predicting job crafting } \\
\text { propensities amongst } \\
\text { administrative employees in } \\
\text { a South African tertiary } \\
\text { institution. SA Journal of } \\
\text { Human Resource } \\
\text { Management/SA Tydskrif vir } \\
\text { Menslikehulpbronbestuur, } \\
\text { 14(1), a702. http://dx.doi. } \\
\text { org/10.4102/sajhrm. } \\
\text { v14i1.702 }\end{array}$} \\
\hline \multicolumn{2}{|l|}{$\begin{array}{l}\text { Copyright: } \\
\text { (C) 2016. The } \\
\text { Licensee: AC } \\
\text { licensed unc } \\
\text { Commons A } \\
\text { License. }\end{array}$} \\
\hline \multicolumn{2}{|l|}{ Read online: } \\
\hline 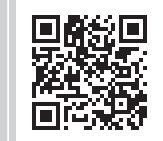 & $\begin{array}{l}\text { Scan this QR } \\
\text { code with your } \\
\text { smart phone or } \\
\text { mobile device } \\
\text { to read online. }\end{array}$ \\
\hline
\end{tabular}

Orientation: Personality provides a foundation for understanding employee job behaviours. It determines and reflects how they respond to their work situations. There is a shortage of previous researches that have specifically dealt with the predictive role of personality on job crafting. Job crafting is also a significantly new concept in the South African work context. It has both positive and negative consequences on employee job behaviours.

Research purpose: The present study investigated the role of big five factors on predicting job crafting propensities amongst administrative employees in Alice, South Africa.

Motivation for the study: The present study aimed to determine the role of big five factors on predicting job crafting propensities amongst administrative employees. It was premised on previous research that the big five factors are associated with many employee job behaviours.

Research approach, design and method: The present study employed a quantitative, crosssectional research design with a sample of 246 administrative employees in Alice, South Africa. A biographical questionnaire, a Big Five Inventory, and a job crafting questionnaire were used to collect data.

Main findings: The findings showed that big five factors of Conscientiousness, Extraversion, Agreeableness, Openness to experience and Neuroticism play a significant role in predicting job crafting propensities.

Practical implications: The present study suggests that big five factors of Conscientiousness, Extraversion, Agreeableness, Openness to experience and Neuroticism have a predictive role on job crafting behaviours. Managers of tertiary institutions can therefore consider these big five personalities to understand and predict the impacts of their job design strategies on administrative employees' behaviours.

Contribution: The contribution of the study was significant in that it contributed to research literature representing the influence of the big five factors in understanding job crafting propensities of employees.

\section{Introduction}

Job crafting is still a new concept even in the South African environment (Vreugdenhil, Kooij \& Van Veldhoven, 2012). Job design on the other hand is a well-researched concept in the field of human resources management. Traditionally, managers were tasked to design jobs in organisations, not always taking individual differences into consideration (Vreugdenhil et al., 2012). Because of employee diversity, it remains a very difficult task for managers to develop an optimal job design to suit the specific needs of all employees (Berg, Dutton \& Wrzesniewski, 2007). These challenges experienced by employees have created an urge to assume the managerial responsibilities of job designing. As a result, employees will typically engage in job crafting behaviours in order to meet their diverse competences and needs (Tims, Bakker \& Derks, 2012). Job crafting is therefore a strategy employed by employees to redesign their jobs (Tims, Bakker \& Derks, 2013). They proactively adjust the attributes of their jobs to optimise the balance between the features of the job and their own needs, competences and preferences (Tims et al., 2013). These researchers also argued that employees create changes in their jobs for three different reasons. Firstly, they redesign their tasks because they want to be satisfied in their jobs. As such, an employee may request for different tasks that need new competences from the supervisor because he or she feels that the job is repetitive and boring. The second reason is that, employees may modify their interpersonal associations they attain when doing their work. The third one is that employees may change their 
own cognitive perceptions towards their work by positively changing their perceptions towards the attributes of the job (Tims et al., 2013). Researchers believe that these job changes enable employees to experience more engagement and meaningfulness in their work (Tims \& Bakker, 2010).

\section{Problem statement}

The University of Fort Hare is still in the process of organisational transformation and development. In managing the transformation processes, the University has also revitalised its organisational development department (Bell, Murugan \& Nel, 2014, p. 1971). Organisational development managers are therefore, heavily involved in redesigning jobs for their employees as part of their functions in the organisation (Vreugdenhil et al., 2012). And, as such, employees are passive recipients of positions they occupy (Wrzesniewski, LoBuglio, Dutton \& Berg, 2013). This development has come with changes in the demands and resources needed in their jobs. However, many employee differences have not been taken into consideration by managers when designing jobs for administrative employees at Fort Hare University (Vreugdenhil et al., 2012). Administrative employees represent an important professional group of employees within the university because they create a climate conducive for the organisation to function at the optimal level. Previous researchers argued that employees are all very diverse, making it difficult for the University in this instance to design jobs for every unique employee's needs (Berg et al., 2007). In response to this problem, administrative employees would typically engage themselves in crafting their job tasks and responsibilities as indicated in their formal job descriptions, either by increasing or decreasing tasks, changing the type of tasks or adjusting the amount of time, effort and attention given to different tasks (Tims et al., 2013). They craft their own jobs to satisfy their competences and needs (Tims et al., 2012). When employees find that there is an inequity between the amount of job demands and job resources, they may be motivated to reduce this incongruence by employing four complementary strategies of job crafting. In other words, when the job does not meet employees' competences or needs, the employees may be motivated to adjust the attributes of the job (Tims et al., 2012). They are more satisfied and effective when they are in positions that align well with their personal attributes. Scholars argue that job crafting is a proactive behaviour to modify the situation or employee himself or herself to attain more fit between the employees' personal attributes and the job situation (Tims et al., 2013). It is about adjustments that employees make in order to achieve their person-job fit and positive work outcomes (Tims et al., 2012). Scholars also argue that, because job crafting is directed towards proactively improving the work situation compared to other people, the organisation and the external environment, it has been classified under proactive personenvironment fit behaviour (Tims et al., 2014). Researchers argued that the big five factors are associated with different employee job behaviours (Ozer \& Benet-Martinez, 2006). Big five factors provide a foundation for understanding the relationship between personality and employee job behaviours (Komarraju, Karau, Schmeck \& Avdic, 2011). However, there is a scarcity of previous researches that have specifically dealt with the relationship between big five factors and job crafting. Previous studies have only focused on proactive personality, self-efficacy and self-regulation as the antecedents in job crafting (Tims \& Bakker, 2010). The present study therefore proposes that the big five traits of employees have a role in either changing job demands or resources, or both of them. Research reveals that employees who craft their job resources enjoy their work more and use these positive feelings to increase their work performance (Tims, Bakker \& Derks, 2014).

\section{Objectives of the study}

The purpose of the present study was to determine the role of the big five factors on predicting job crafting propensities amongst Fort Hare University administrative employees.

\section{Literature review}

\section{Theoretical perspectives}

Big five theory: The past 30 years have seen an increase in personality research (Funder, 2001). The big five theory is a significant theory that has been extensively used in research of employee work behaviour (McCrae \& Costa, 2003; Mondak, 2010; Ozer \& Benet-Martinez, 2006). It has provided the most developed practical use of the big five personality factors to date (Costa \& McCrae, 1992). The basis of the theory is the notion that personality can be condensed into five critical factors (Fincham \& Rhodes, 2005). The big five factors are Conscientiousness, Extraversion, Agreeableness, Openness to experience and Neuroticism (Costa \& McCrae, 1992). It provides a very important foundation for determining the association between personality and job behaviours (Komarraju et al., 2011).

Job Demands-Resources model: Job attributes that need sustained energy from employees and which are linked with certain costs are called job demands. And the job attributes that add value towards achieving work-related goals, reducing the impact of job demands and associated costs and producing personal growth and development are referred to as job resources (Tims et al., 2013, p. 231). According to Tims et al. (2013), job crafting involves making adjustments in the job description. It is, therefore, explained by using the types of job attributes offered by the Job Demands-Resources (JD-R) model (Bakker \& Demerouti, 2007): job demands and job resources (Tims et al., 2012). The classification enables the researchers to determine which job attributes employees adjust when they craft their jobs. Consistent with the JD-R model, job crafters change either the level of job demands, the level of job resources and/or both (Tims et al., 2013, p. 231). Based on the JD-R model, scholars propose that job crafting has four conceptually different dimensions, namely: increasing structural job resources (ISTJR), decreasing hindering job demands (DHJD), increasing social job resources (ISJR) and increasing challenging job demands (ICJD) (Tims et al., 2012). 
Person-job fit theory: This theory deals with the degree at which a particular job matches employees' competences, interest and personalities (Greenberg, 2011). In this regard, an employee will be more effective to the extent that there is congruence between him or her and the job attributes. The theory suggests that the less the congruence between employees' attributes (personalities) and those required in their jobs, the more they may engage in job crafting behaviours in their organisations to achieve a person-job fit (Greenberg, 2011).

\section{Definitions of concepts}

Job crafting: It is defined as the 'self-initiated change behaviours that employees engage in with the aim to align their jobs with their own preferences, motives, and passions' (Tims et al., 2012, p. 173). It is perceived as a specific type of initiative work behaviour that employees engage in to modify their job tasks to suit their needs, competences and preferences (Tims et al., 2013). Other scholars also perceived it as:

the physical and cognitive modifications that employees make in the job task or interpersonal frameworks of their work which directs attention to the proactive, bottom-up strategies employed by employees to change the task, relational, and cognitive frameworks of their jobs. (Berg, Wrzesniewsk \& Dutton, 2010, p. 179)

It requires the behaviours that employees engage in to modify their job tasks to promote job satisfaction, job engagement, resilience and work thriving (Berg et al., 2007). The main attribute of job crafting in the work environment implies that employees initiate and carry out adjustments in their job tasks from the bottom-up, rather than managers directing changes from the top-down (Berg et al., 2007). Job crafters can proactively modify the scope of their job by means of four strategies: (Tims et al., 2012).

Increasing structural job resources: It refers to increasing resources of variety, opportunity for development and autonomy (Tims et al., 2012).

Decreasing hindering job demands: It is the situation where employees proactively reduce or lessen their job demands when they perceive them as becoming overwhelming. They introduce initiatives to decrease their level of job demands (Tims et al., 2012).

Increasing social job resources: It is when an employee increases the resources of social support, supervisory coaching and feedback (Tims et al., 2012).

Increasing challenging job demands: It implies that employees develop their competences to achieve more difficult goals in order to increase personal growth and satisfaction in the job (Tims et al., 2012).

\section{Personality: It is defined as the:}

constellation of psychological attributes and mechanisms within an employee that are organised and relatively stable, and that affects his or her involvement with, and adaptations to, the intrapsychic, physical, and social environments. (Larsen \& Buss, 2010, p. 4)

It is a relatively unchanging integration of traits which makes an employee unique and also produces consistencies in his or her thoughts and behavioural actions (Fincham \& Rhodes, 2005). It is also viewed by other scholars as the inner psychological factors that both control and reflect how an employee responds to different work situations. These inner psychological characteristics are therefore, those specific qualities, attributes, traits, factors and mannerisms that separate one employee from another (Schiffman \& Kanuk, 2007). Researchers argue that personality traits may affect job behaviours because employees are actively changing their work environments (Roberts, Kuncel, Shiner, Caspi \& Goldberg, 2007). Lounsbury et al. (2003) are of the opinion that personality is very critical in explaining variations in job behaviours.

\section{Conscientiousness and job crafting propensities}

Conscientiousness is defined as the tendency of an employee to show self-discipline and to strive for competence and achievement (Greenberg, 2011). This dimension of personality is explained by narrow traits such as being well-organised, careful, self-disciplined, responsible and precise at the high end and being disorganised, impulsive, careless and undependable at the low end. Other scholars perceived it as a broad underlying factor that is explained by narrower traits such as obedience, persistence, impulse control, planning and organising, perfectionism and integrity (Fincham \& Rhodes, 2005). Moreover, a conscientious employee has a set of emotional control that promotes responsibility and goaldirected work behaviours. There is a shortage of previous research that has linked Conscientiousness and job crafting. The attributes of a conscientious employee suggest that this type of employee may have lesser tendencies to engage in job crafting behaviours. However, this type of employee is highly engaged with the job (Schaufeli, 2013). The employee is less likely to change the job characteristics in a way that contributes towards achieving work-related goals because he or she adheres to standards set and has a strong and deeply embedded work ethic that developed during his or her childhood (Bell \& Murugan, 2013). As such, a conscientious employee is less likely to change the level of job demands, job resources or both (Tims et al., 2013). This type of employee may not engage in job crafting strategies like changing the set of responsibilities and tasks specified by a formal job description, by increasing or decreasing tasks, adjusting the types of tasks or changing the amount of time, effort and attention given to various tasks (Tims et al., 2013). These extant arguments therefore suggest the following hypothesis:

- Hypothesis 1: Conscientiousness has a nonsignificant role in predicting job crafting propensities.

\section{Extraversion and job crafting propensities}

Extraversion is defined as the propensity of a person seeking stimulation, and enjoying the association of others 
(Greenburg, 2011). This dimension is explained by narrow traits such as energetic, sober, socially confident and cheerful, enthusiastic, sociable and talkative at the high end, and to retiring, reserved, silent, and cautious, selfcontained, serious minded and somewhat aloof at the low end (Greenburg, 2011; Fincham \& Rhodes, 2005). Scholars argue that an employee who has high Extraversion is more inclined towards positive effect and values interpersonal associations more than other employees (Matzler, Faullant, Renzl, \& Leiter, 2005). Currently, there is a shortage of previous researches confirming a link between Extraversion and job crafting tendencies. However, the behavioural attributes suggest that there may be involvement on job crafting activities. For instance, because this type of employee values more interpersonal relations and has a greater energy expended on behavioural tendencies of the world (John \& Srivastava, 1999), the individual may modify the job if it does not satisfy these interpersonal needs. This type of employee may therefore, employ job crafting strategies to harness the needs. As such, the employees may change how, when or the people they interact with when they perform their jobs (Berg et al., 2007). These arguments therefore lead to the following hypothesis:

- Hypothesis 2: Extraversion has a significant role in predicting job crafting tendencies.

\section{Agreeableness and job crafting propensities}

Agreeableness is defined as the degree to which an employee is cooperative, forgiving, compassionate, understanding and trusting (Fincham \& Rhodes, 2005). It is, therefore, explained by narrow factors such as being cooperative, altruism, tendermindedness, trust, modesty caring, sympathetic, kind and affectionate, and likeable (John \& Srivastava, 1999; Mehmetoglu, 2012). Currently, there is a shortage of previous researches that have confirmed the link between this personality dimension and job crafting tendencies. However, the behavioural attributes of an agreeable employee suggest that this individual may be less likely to engage in job crafting tendencies. For instance, because the employee is cooperative, understanding and trusting, he or she may be less likely to craft their job tasks (Fincham \& Rhodes, 2005). The employee may not engage in modifying the tasks and responsibilities as they are spelt out in a formal job description, by increasing or decreasing tasks, changing the type of tasks or adjusting the amount of time, effort and attention given to different tasks (Tims et al., 2013). As such, the present study proposed the following hypothesis:

- Hypothesis 3: Agreeableness has a nonsignificant role on predicting job crafting tendencies.

\section{Openness to experience and job crafting propensities}

Openness to experience is defined as the breadth, depth, originality and complexity of an employee's cognitive maps and experiential behaviour (John \& Srivastava, 1999). It describes employees who are open to change their own perspectives and what they want from others (Mondak, 2010). Moreover, scholars also see it as an active fantasy, aesthetic sensitivity, attentiveness to emotions and preference for diversity, intellectual curiosity and independence of judgement (Costa \& McCrae, 1992). Employees with a high level of openness are attracted to both what is happening within themselves and in their external worlds. They are keen to accept novel perceptions and unusual values. Furthermore, they experience both positive and negative emotions more keenly as compared to employees who are not open (Costa \& McCrae, 1992). They also show intellectual curiosity, creativity and flexible cognitive structure (Dingman, 1990). There is a shortage of previous researches that have confirmed the link between this personality dimension and job crafting tendencies. However, the behavioural attributes of an open employee suggest that the individual may be highly engaged in job crafting behaviours. For instance, because this type of employee has flexible cognitive maps and experiential tendencies, is open to one's own perspectives and has an active fantasy (John \& Srivastava, 1999; Mondak, 2010; McCrae, 1992), it is highly probable to employ job crafting strategies. As such, this employee may proactively change the ways he or she perceives job tasks and relationships that compose the job (Berg et al., 2007). These extant arguments therefore yield to the following hypothesis:

- Hypothesis 4: Openness to experience has a significant role in predicting job crafting tendencies.

\section{Neuroticism and job crafting propensities}

Neuroticism is defined as a predisposition of an employee towards lack of positive psychological adjustment and emotional stability (John \& Srivastava, 1999). It is therefore associated with instability, stress proneness, personal insecurity and depression (Mehmetoglu, 2012). Scholars argue that emotionally stable employees are not easily affected by anxiousness, nervousness, sadness and being tensed (John \& Srivastava, 1999). They act after making a conscious decision about their job behaviour pattern. Poor self-regulating potency is the dispositional attribute of Neuroticism (LaRose \& Eastin, 2002). There is a shortage of previous researches that have confirmed the link between this personality dimension and job crafting tendencies. However, the behavioural attributes of a neurotic or emotional unstable employee suggests that this individual is highly likely to engage in job crafting behaviours. Scholars argue that employees who are emotionally unstable sometimes modify their job task to manage their emotions (Bosnjak, Galesic \& Tuten, 2007). Due to of lack of positive psychological adjustment and emotional stability, high stress proneness, personal insecurity and depression (John \& Srivastava, 1999; Mehmetoglu, 2012), this employee is highly likely to engage in job crafting strategies to manage the emotional weaknesses (Bosnjak et al., 2007). These extant arguments therefore lead the following hypothesis:

- Hypothesis 5: Neuroticism has a significant role in predicting job crafting tendencies. 


\section{Methods}

\section{Research participants}

A nonprobability sampling method was employed to select respondents from the population. Nonprobability sampling refers to a sampling method through which the choice of elements is not based on the statistical element of randomness (Durheim \& Painter, 2006). As such, a convenience sampling technique was used. It is simply defined as the process where a researcher uses any member of the population who is available during the research process without considering their criteria (Welman, Kruger, \& Mitchell, 2005). It involved selecting haphazardly those administrative employees who were easiest to obtain for the sample. The sample selection process continued until the required sample size was achieved.

The University of Fort Hare's administration has 676 administrative employees. This includes employees from the Human Resources, Finance, Registrar, Student Administration, Communications and Marketing, Examinations, Payroll, Library, Information Technology, Accommodation, Maintenance, and Institutional Support departments. Using the Raosoft sample size calculator at 5\% margin of error and $95 \%$ confidence interval, the sample size for administrative employees was $N=246$. This is the minimum recommended sample size by the Raosoft sample size calculator (Raosoft Inc, 2004). However, the researcher distributed 286 questionnaires to the subjects and 246 questionnaires were fully completed. This resulted in a $66.7 \%$ response rate. Amongst the sample group, $59.35 \%$ were female subjects and $40.65 \%$ were male subjects. With regards to age, $33.3 \%$ were in the age group $20-29 ; 26.83 \%$ were in the age group $30-39$; $21.95 \%$ were in the age group $40-49 ; 15.85 \%$ were in the age group 50-59 and 2.03\% were in the age group 60 and above. Also with regards to education levels, $6.91 \%$ had a high school qualification, $13.01 \%$ had a certificate, $15.45 \%$ had a diploma, $36.18 \%$ had a degree and $28.46 \%$ had a postgraduate degree. Lastly, but not least, with regards to home languages, 70.33 indicated that they were Xhosa speaking, 6.91 were speaking Zulu, 10.57 were speaking Afrikaans; 6.91 were speaking English and 5.28 were speaking Sepedi. The demographic characteristics of the participants are presented in Table 1.

\section{Measuring instruments}

The data collection method for the present study was made up of the big five questionnaire, job crafting questionnaire and a biographical questionnaire, which was developed by the researcher. A biographical questionnaire was only used to collect some demographic information of the participants in this study. As such, this information was collected on gender, age groups, education level and home languages of the participants.

\section{Big five questionnaire}

To assess the factors of Conscientiousness, Extraversion, Agreeableness, Openness to experience and Neuroticism, the appropriate subscales of the Big Five Inventory adopted
TABLE 1: Demographic characteristics of the participants.

\begin{tabular}{llcc}
\hline Variable & Participant characteristics & Frequency & \% \\
\hline Gender & Female & 146 & 59.35 \\
Age & Male & 100 & 40.65 \\
& $20-29$ & 82 & 33.33 \\
& $30-39$ & 66 & 26.83 \\
& $40-49$ & 54 & 21.95 \\
Education level & $50-59$ & 39 & 15.85 \\
& $60<$ & 5 & 2.03 \\
& High school & 17 & 6.91 \\
& Certificate & 32 & 13.01 \\
& Diploma & 38 & 15.45 \\
& Degree & 89 & 36.18 \\
Home language & Postgraduate degree & 70 & 28.46 \\
& Xhosa & 173 & 70.33 \\
& Zulu & 17 & 6.91 \\
& Afrikaans & 26 & 10.57 \\
& English & 17 & 6.91 \\
& Sepedi & 13 & 5.28 \\
\hline
\end{tabular}

$n=246$.

from John, Donahue and Kentle (1991) were used. This is a 44-item scale that was designed to represent the sample definitions created by specialist evaluations and subsequent factor analytic authentication in assessor personality ratings (John \& Srivastava, 1999). These researchers found the Cronbach's alpha coefficients for the subscales of big five factors to be $0.82,0.88,0.79,0.84$ and 0.81 , respectively. The respondents used a 5-point Likerttype scale, which ranged from strongly disagree (1) to strongly agree (5).

\section{Job crafting questionnaire}

To assess the extent at which employees engage in job crafting behaviours, a scale adopted from Tims et al. (2012) was employed. The scale has 21 items that measure the four dimensions of job crafting: ISTJR, DHJD, ISJR and ICJD. Tims et al. (2012) found the Cronbach's alpha coefficients for the job crafting dimensions to be 0.82 , $0.79,0.77$ and 0.75 , respectively. The respondents used a 5 -point frequency scale, which ranged from never (1) to often (5).

\section{Research design}

The present study employed a quantitative, cross-sectional research design with a survey research method. Quantitative research design strongly makes use of empirical analysis to make conclusions, and it enables the researcher to test hypotheses (Hair, Wolfinbarger, Ortinau \& Bush, 2008). Cross-sectional research design refers to:

a criterion groups design in which the different criterion groups are typically comprised of different age groups which are examined in terms of one or more variables at approximately the same time. (Huysamen, 1994, p. 98)

A quantitative research design was the most preferred research design because the researcher aimed to determine the predictive role of the big five factors on job crafting propensities. 


\section{Research procedure}

The permission to conduct research on the organisation's administrative employees was obtained from the human resources director. As such, an informed letter of consent and a sample of the research questionnaire were submitted to the human resources director. Furthermore, a meeting between the researchers and the human resources director was organised during which the researchers explained the objectives of the research. The researchers were granted permission to collect research data during a 1-month period. The administrative employees were asked by the researchers to participate in the research on a voluntary basis. Employees who were willing to participate in the research were given questionnaires, which included a letter to explain to the employees the purpose of the research, the procedure of participation in the research and issues of confidentiality and anonymity. They were also given an informed consent form before participating in the research. The collection of data took place over a period of a month as it was agreed with the human resources director. This gave the participants enough time to complete the questionnaires at their convenience. The completed research questionnaires were collected by the researchers.

\section{Statistical analysis}

To analyse data, the Statistical Package for the Social Sciences (SPSS), version 21, and the Statistical Analysis Software were employed. Descriptive statistics were analysed by determining the minimum and maximum scores, standard deviations and means. The skewness was also measured to determine the symmetry of the distribution. Cronbach's alpha reliabilities were calculated to determine the internal consistency and reliability of the scales of the questionnaires. Scholars agreed that Cronbach's alpha coefficients should be greater than 0.70 in order to be considered to have an acceptable level of internal consistency (Nunnally \& Bernstein, 1994).

An exploratory factor analysis (EFA) was performed to examine construct validity. Factor analysis is defined as a 'specialised statistical technique that is particularly useful for investigating construct validity' (Gregory, 2007, p. 135). Before an EFA was performed on the big five questionnaire, items $2,6,8,9,12,18,21,23,24,27,31,34,35,37,41$ and 43 were reversed. Factor analysis was conducted on the big five questionnaire and the job crafting questionnaire to determine the underlying factors in the scales. The big five questionnaire consists of five subscales, and a job crafting questionnaire consists of four subscales. It was therefore important to assess which factors best represented data in the present study. The analysis of constructs aims to determine whether the constructs are homogeneous, which means that they are able measure one construct (Gregory, 2007).

Inferential statistics were also used to analyse data because inferences were made about the population from its sample. A standard multiple regression analysis was performed to determine whether big five factors had predictive values for job crafting. As such, the hypotheses were accepted and rejected using the multiple regression values. Pearson correlation coefficient was used to determine the relationship between the big five factors and job crafting. Practically significant relationships were measured to ascertain 'whether a relationship is large enough to be important' (Steyn, 2002, p. 10).

\section{Results}

EFA was performed on 41 items of the BFQ and 21 items of the JCQ. EFA was preferred because the present study used a small sample of 246 and was designed to make an additive contribution to the body of knowledge on big five personality and job crafting amongst administrative employees in an institution environment. This information is important for those refining future research in these subjects areas. This is therefore an exploratory and investigative work from which tentative findings can be deducted instead of conclusive patterns. Macro-level researches should be conducted to confirm these findings before strong conclusions can be made about a South African environment at large.

A principal component analysis was performed on 44 items of the BFQ, which revealed that five factors emerged from the data (see Table 2). The factors are Conscientiousness, Extraversion, Agreeableness, Open to experience and Neuroticism. The Keizer-Meyer-Olkin value was 0.71 , which exceeds the threshold value of 0.6, and the Bartlett's test of sphericity indicated a statistical significance. A fivecomponent solution explained a total of $100 \%$ of the variance, with component one contributing $47.5 \%$, two contributing $21.0 \%$, three contributing $13.4 \%$, four contributing $10.4 \%$ and five contributing $7.7 \%$ of the total variance. These factor analysis results are also consistent with the findings of John and Srivastava (1999) and Benet-Martinez and John (1998). They found that the big five factors taxonomy is similar across different types of samples.

In Table 2 for the JCQ, the results of factor analysis also showed that four factors emerged. The factors that emerged are ISTJR, DHJD, ISJR and ICJD. The Keizer-Meyer-Olkin value was 0.60 , which exceeds the threshold value of 0.6 , and the Bartlett's test of sphericity indicated a statistical significance. A four-component solution explained a total of $100 \%$ of the variance, with component one contributing

TABLE 2: Initial eigenvalues for the total variances explained.

\begin{tabular}{lcccc}
\hline Questionnaire & Component & \multicolumn{3}{c}{ Initial Eigenvalues } \\
\cline { 2 - 5 } & & Total & \% of variance & Cumulative \% \\
\hline Big Five Inventory & 1 & 2.375 & 47.509 & 47.509 \\
& 2 & 1.051 & 21.014 & 68.523 \\
& 3 & 0.669 & 13.372 & 81.895 \\
& 4 & 0.522 & 10.445 & 92.340 \\
Job Crafting Questionnaire & 1 & 2.221 & 55.525 & 55.525 \\
& 5 & 0.383 & 7.660 & 100.000 \\
& 2 & 0.978 & 24.439 & 79.964 \\
& 3 & 0.602 & 15.047 & 95.010 \\
& 4 & 0.200 & 4.990 & 100.000 \\
\hline
\end{tabular}


$55.5 \%$, two contributing $24.4 \%$, three contributing $15.0 \%$ and four contributing $4.10 \%$ of the total variance. Tims et al. (2012) also found that job crafting can be measured by four factors.

Table 3 shows the descriptive statistics of the variables that were studied. The negative skewness values indicate that the distribution is negatively skewed. As such, most scores cluster around high scores on the distribution. These skewness values show that the distribution is normally distributed. Cronbach's alpha coefficients were used to test the reliability of BFQ and JCQ. According to researchers, Cronbach's alpha coefficients should be greater than or equal to 0.70 to be considered as reliable and acceptable (Nunnally \& Bernstein, 1994). The Cronbach's alpha coefficients for the questionnaires and the subscales are also shown in Table 3. Cronbach's alpha reliability for the BFQ was 0.81, with a Conscientiousness dimension recording 0.77, Extraversion dimension recording 0.79, Agreeableness dimension recording 0.81, Openness to experience dimension recording 0.84 and Neuroticism dimension recording 0.83 . Cronbach's alpha reliability for the JCQ was 0.87 , with a ISTJR dimension recording 0.92 , DHJD dimension recording 0.88 , ISJR dimension recording 0.85 and ICJD dimension recording 0.83. All the Cronbach's alpha coefficients were therefore greater than a 0.70 standard acceptable.

Table 4 also shows the results of the Pearson correlation coefficient analysis. The Pearson correlation coefficient analysis was employed to determine the relationship between the big five factors (as measured by BFQ) and job crafting (as measured by JCQ). Conscientiousness was found to have a statistically and practically nonsignificant relationship with job crafting $(r=-0.05133 ; p=0.4229)$. For the dimensions of job crafting, ISTJR $(r=0.02593 ; p=0.6857)$, $\operatorname{ISJR}(r=0.15202 ; p=0.0170)$ and ICJD $(r=-0.07045 ; p=0.2710)$, Conscientiousness was found to have a statistically and practically nonsignificant relationship as well. However, with DHJD ( $r=-0.23797 ; p=0.0002)$, Conscientiousness was found to have a statistically and practically significant relationship. Extraversion was also found to have a statistically and practically significant relationship with job crafting $(r=-0.29627 ; p=0001)$. For DHJD ( $r=-0.45990$; $p=0.0001)$ and ISJR $(r=-0.24025 ; p=0.0001)$ dimensions, Extraversion was found to have a statistically and practically significant relationship as well. However, for ISTJR $(r=-0.04680 ; p=0.4650)$ and ICJD $(r=0.07242 ; p=0.2578)$ dimensions, Extraversion was found to have a statistically and practically nonsignificant relationship.

Agreeableness was also found to have a statistically and practically significant relationship with job crafting $(r=-0.31456 ; p=0001)$. For DHJD $(r=-0.25730 ; p=0.0001)$, ISJR $(r=-0.42933 ; p=0.0001)$ and ICJD $(r=-0.16752$; $p=0.0085)$ dimensions, Agreeableness was found to have a statistically and practically significant relationship as well. However, for ISTJR ( $r=-0.01119 ; p=0.8614)$, Agreeableness has a statistically and practically nonsignificant relationship. Openness to experience was also found to have a statistically and practically significant relationship with job crafting $(r=-0.35658 ; p=0.0001)$. For DHJD $(r=-0.25353 ; p=0.0001)$, ISJR $(r=-0.34298 ; p=0.0001)$ and ICJD $(r=-0.27132$; $p=0.0001$ ) dimensions, Openness to experience was found to have a statistically and practically significant relationship. However, with ISTJR $(r=-0.14585 ; p=0.0221)$, Openness to experience has a statistically and practically nonsignificant relationship.

TABLE 3: Descriptive statistics and reliability statistics for the scales.

\begin{tabular}{|c|c|c|c|c|c|c|}
\hline Variable & M & SD & Min & Max & Skewness & $\alpha$ \\
\hline 1. Conscientiousness & 37.03 & 4.66 & 27 & 43 & -0.49 & 0.77 \\
\hline 2. Extraversion & 25.74 & 4.28 & 19 & 32 & -0.01 & 0.79 \\
\hline 3. Agreeableness & 35.73 & 5.77 & 27 & 45 & 0.07 & 0.81 \\
\hline 4. Openness to experience & 38.15 & 4.14 & 31 & 45 & 0.17 & 0.84 \\
\hline 5. Neuroticism & 19.04 & 4.56 & 9 & 26 & -0.38 & 0.83 \\
\hline 6. ISTJR & 19.62 & 4.29 & 5 & 25 & -1.42 & 0.92 \\
\hline 8. ISJR & 18.97 & 4.00 & 10 & 25 & -1.01 & 0.85 \\
\hline 9. ICJD & 20.83 & 2.22 & 15 & 25 & -1.01 & 0.83 \\
\hline 10. Job crafting total & 83.76 & 10.61 & 48 & 105 & -1.48 & 0.87 \\
\hline 11. Big five total & 155.69 & 11.98 & 138 & 190 & 1.14 & 0.81 \\
\hline
\end{tabular}

M, mean; SD, standard deviation; Min, minimum; Max, maximum, $\alpha$, alpha; ISTJR, increasing structural job resources; DHJD, decreasing hindering job demands; ISJR, increasing social job resources; ICJD, increasing challenging job demands.

TABLE 4: Correlations matrix between big five factors and job crafting variables.

\begin{tabular}{|c|c|c|c|c|c|c|c|c|c|c|}
\hline \multirow[t]{2}{*}{ Variables } & \multicolumn{2}{|c|}{ ISTJR } & \multicolumn{2}{|c|}{ DHJD } & \multicolumn{2}{|c|}{ ISJR } & \multicolumn{2}{|c|}{ ICJD } & \multicolumn{2}{|c|}{ Job crafting Total } \\
\hline & $r$-value & $p$-value & $r$-value & $p$-value & $r$-value & $p$-value & $r$-value & $p$-value & $r$-value & $p$-value \\
\hline 1. Conscientiousness & 0.02593 & 0.6857 & -0.23797 & $0.0002 * *$ & 0.15202 & 0.0170 & -0.07045 & 0.2710 & -0.05133 & 0.4229 \\
\hline 2. Extraversion & -0.04680 & 0.4650 & -0.45990 & $<0.0001 * *$ & -0.24025 & $<0.0001 * *$ & 0.07242 & 0.2578 & -0.29627 & $<0.0001^{* *}$ \\
\hline 3. Agreeableness & -0.01119 & 0.8614 & -0.25730 & $<0.0001 * *$ & -0.42933 & $<0.0001 * *$ & -0.16752 & $0.0085^{*}$ & -0.31456 & $<0.0001 * *$ \\
\hline 4. Openness to experience & -0.14585 & 0.0221 & -0.25353 & $<0.0001 * *$ & -0.34298 & $<0.0001 * *$ & -0.27132 & $<0.0001 * *$ & -0.35658 & $<0.0001 * *$ \\
\hline 5. Neuroticism & -0.00435 & 0.9459 & 0.56202 & $<0.0001 * *$ & 0.00186 & 0.9768 & 0.25881 & $<0.0001 * *$ & 0.29981 & $<0.0001 * *$ \\
\hline
\end{tabular}

ISTJR, increasing structural job resources; DHJD, decreasing hindering job demands; ISJR, increasing social job resources; ICJD, increasing challenging job demands.

$N=246 ;$
$*, p<0.05$, statistically significant; $* *, p<0.01$, statistically significant 
In addition, Neuroticism was also found to have a statistically and practically significant relationship with job crafting $(r=0.29981 ; p=0.0001)$. For DHJD $(r=0.56202$; $p=0.0001)$ and ICJD $(r=0.25881 ; p=0.0001)$ dimensions, Neuroticism was also found to have a statistically and practically significant relationship. However, for ISTJR $(r=-0.00435 ; p=0.9459)$ and ISJR $(r=0.00186 ; p=0.9768)$ dimensions, Neuroticism has a statistically and practically nonsignificant relationship. Furthermore, total big five was found to have a statistically and practically significant relationship with job crafting $(r=-0.28658 ; p=0.0001)$. For DHJD $(r=-0.25461 ; p=0.0001)$ and ISJR $(r=-0.35145$; $p=0.0001)$ dimensions, total big five has a statistically and practically significant relationship as well. However, for ISTJR $(r=-0.06409 ; p=0.3167)$ and ICJD $(r=-0.07763$; $p=0.2251)$ dimensions, total big five has a statistically and practically nonsignificant relationship.

Table 5 shows the results of a standard multiple regression. A standard multiple regression was used to determine the extent at which the big five factors of Conscientiousness, Extraversion, Agreeableness, Openness to experiences and Neuroticism predicted job crafting. The aim was to find out the unique contributions of each factor on job crafting. As shown in Table 4 , the regression model accounted for $30.6 \%$ of the variance $\left(R^{2}=0.306 ; F=21.172 ; p=0.001\right)$. The present study found that Conscientiousness was a statistically and practically significant predictor of job crafting $(\beta=0.299$; $t=4.28 ; p=0.0001)$. This finding therefore implies that hypothesis 1 was rejected. Agreeableness was also found to be a statistically and practically significant predictor of job crafting $(\beta=-0.283 ; t=4.17 ; p=0.0001)$. This finding therefore means that hypothesis 3 was supported. In addition, Openness to experience was also found to be a statistically and practically significant predictor of job crafting $(\beta=-0.305 ; t=-5.50 ; p=0.0001)$. This finding implies that hypothesis 4 was also confirmed. Furthermore, Neuroticism was also found to be a statistically and practically significant predictor of job crafting $(\beta=-0.327 ; t=5.06 ; p=0.0001)$. This finding means that hypothesis 5 was also confirmed. However, Extraversion was found to be a statistically and practically nonsignificant predictor of job crafting $(\beta=-0.085 ; t=-1.26 ; p=0.2106)$. This finding therefore means that hypothesis 2 was rejected. The Beta weights coefficients of the big five factors also revealed that Neuroticism was the highest predictor of job crafting, followed by Openness to experience, Agreeableness, Conscientiousness, and lastly, Extraversion.

\section{Discussion}

The purpose of the present study was to determine the role of big five factors on predicting job crafting propensities amongst Fort Hare University's administrative employees. Big five factors have been found to be associated with many job behaviours (Ozer \& Benet-Martinez, 2006). They provide a very important foundation for determining the role of personality on job crafting behaviours (Komarraju et al., 2011). The big five factors of personality are Conscientiousness, Extraversion, Agreeableness, Openness to experience and Neuroticism (Mehmetoglu, 2012).

The multiple regression analysis results revealed that Conscientiousness has a statistically and practically significant role on predicting job crafting propensities. Conscientious administrative employees within a tertiary institution environment engage in job crafting behaviours. This finding is uncommon because the attributes of conscientious individuals are not congruent with job crafting behaviours. Moreover, the Pearson correlation results of the present study also revealed that Conscientiousness and job crafting variables are statistically and practically nonsignificantly related. There is a shortage of previous studies that have been conducted to relate these variables. However, researchers found that conscientious individuals adhere to standards set and have a strong and deeply embedded work ethic that developed when they were still young (Bell \& Murugan, 2013). As such, they are not likely to adjust their formal job descriptions to suit their needs, skills and preferences (Tims et al., 2013). The findings of the present study therefore make the study an important one, and more research is needed to confirm the predictive validity of a conscientious personality on job crafting.

The multiple regression analysis results also showed that Extraversion has a statistically and practically nonsignificant role on predicting job crafting behaviours. Extraverted administrative employees within a tertiary institution environment do not engage themselves in job crafting activities. This finding is very unique because the attributes of an extraverted individual are congruent with job crafting behaviours. The Pearson correlation results of the present study also showed that Extraversion and job crafting are statistically and practically significantly associated. These findings therefore make the present study important. However, there is a shortage of previous studies that have been conducted to link Extraversion and job crafting. And more research is also needed to confirm the predictive

TABLE 5: Coefficients showing the relative contribution of each of the dimensions of big five factors in predicting job crafting.

\begin{tabular}{|c|c|c|c|c|c|}
\hline \multirow[t]{2}{*}{ Model } & \multicolumn{2}{|c|}{ Unstandardised Coefficients } & \multirow[t]{2}{*}{ Standardised Coefficients $(\beta)$} & \multirow[t]{2}{*}{$t$} & \multirow[t]{2}{*}{ Significance } \\
\hline & $\beta$ & Standard error & & & \\
\hline Constant & 97.880 & 8.882 & & 11.02 & 0.0001 \\
\hline Conscientiousness & 0.682 & 0.159 & 0.299 & 4.28 & 0.0001 \\
\hline Extraversion & -0.212 & 0.169 & -0.085 & -1.26 & 0.2106 \\
\hline Agreeableness & -0.521 & 0.125 & -0.283 & -4.17 & 0.0001 \\
\hline Openness to exp. & -0.782 & 0.142 & -0.305 & -5.50 & 0.0001 \\
\hline Neuroticism & 0.762 & 0.151 & 0.327 & 5.06 & 0.0001 \\
\hline
\end{tabular}

$\beta$, Beta; $t$ - $t$-test. 
validity of an Extraversion personality on job crafting. Researchers found that extraverted individuals value interpersonal relations, and have greater energetic behavioural tendency towards the world (Bono, \& Judge, 2004). As such, extraverted individuals are more likely to craft their jobs if they do not satisfy their interpersonal needs and competences.

The multiple regression analysis results also revealed that Agreeableness has a statistically and practically significant role on predicting job crafting propensities. Agreeable administrative employees within a tertiary institution therefore engage themselves in self-initiated change behaviours with the aim to align their jobs with their own preferences, motives and passions. The Pearson correlation results of the present study also found that Agreeableness and job crafting are statistically and practically significantly related. There is a shortage of previous studies that have been conducted to link these variables. The results of the present study also make the study a unique one. The attributes of agreeable individuals in general suggest that such individuals are not likely to engage in self-initiated change behaviours on their jobs because they are prosocial and cooperative (Fincham \& Rhodes, 2005).

Furthermore, the multiple regression analysis results also showed that Open to experience has a statistically and practically significant role on predicting job crafting behaviours. Openness to experience administrative employees within a tertiary institution environment engage themselves in job crafting behaviours. The Pearson correlation results of the present study also found that Openness to experience and job crafting are statistically and practically significantly associated. There is a shortage of previous studies that have been conducted to link these variables, and this makes the findings of the present study important. However, the attributes of Openness to experience individuals are more congruent with job crafting behaviours. Such individuals have a flexible cognitive map and experiential tendencies, are open to their own perspectives and have an active imagination power (Mondak, 2010). As such, they could change their job tasks and responsibilities prescribed in their job formal descriptions to satisfy their own needs, competences and preferences (Tims et al., 2013). More researches are needed in the South African environment to confirm the predictive validity of Openness to experience on job crafting behaviour.

Lastly, the multiple regression analysis results also indicated that Neuroticism has a statistically and practically significant role on predicting job crafting propensities. Neurotic or unstable administrative employees within an institution craft their jobs tasks and responsibilities. The Pearson correlation results of the present study also showed that Neuroticism and job crafting are statistically and practically significantly related. There is a shortage of previous studies that have been conducted to link these variables, and this makes the subject areas worthy of more research. However, the attributes of neurotic or unstable individuals are more congruent with job crafting behaviours. Such individuals lack positive psychological adjustment and emotional stability (Greenberg, 2011). They have a high level of instability, stress proneness, personal insecurity and depression (Mehmetoglu, 2012). As such, they could engage in job crafting strategies to manage their emotional weaknesses (Berg et al., 2007; Bosnjak et al., 2007). More researches are also needed to confirm the predictive validity of Neuroticism on job crafting.

\section{Practical implications}

The present study suggests that having knowledge of the predictive role of the big five factors on job crafting may help managers of tertiary institutions to understand the impact of their job design interventions on administrative employees. Employees engage in job crafting in response to the ways in which their jobs have been designed for them by managers (Tims et al., 2012). The present study may therefore help managers to understand the informal job-related behaviours that administrative employees within a tertiary institution environment engage themselves in as they attempt to achieve a more optimal job functionality (Wrzesniewski et al., 2013). This study found that administrative employees within a tertiary institution environment with a conscientious, agreeable, open to experience or neurotic personality engage themselves in job crafting behaviours. As such, they increase structural job resources, decrease hindering job demands, increase social job resources and increase challenging job demands.

Because this study and other previous studies have confirmed that employees engage in job crafting behaviours, this study suggests that managers of tertiary institutions should involve administrative employees when designing their jobs. They should employ participative management strategies to allow administrative employees to contribute to their job designs. Such strategies may enable managers to bridge the differences between their preferences as managers and the administrative employees' preferences. The present study also suggests that managers of tertiary institutions may formalise job crafting because it improves the well-being of employees. This may be achieved when employees are allowed craft their job demands and resources (Tims et al., 2011).

\section{Limitations of the study}

Several limitations need to be considered when the results of the present study are interpreted. Firstly, the sample used was confined to a relatively small group of an institution's administrative employees. This therefore limits the application of the research results to the populations of different organisations. Testing the variables on different organisations may help to make strong conclusions about the predictive validity of big five factors on job crafting. Secondly, the present study employed self-reported questionnaires to collect data. This means that participants may have responded to the questionnaires in a socially desirable manner and may therefore not have given accurate responses that reflected 
themselves and their real situations about themselves. Thirdly, the present study used a nonprobability convenience sampling method, which also limits the generalisability of results to other organisations. Finally, the cross-sectional nature of the present study limits the nature of data obtained to a specific period of time.

\section{Recommendations for future research}

The present study recommends that longitudinal studies should be conducted to elicit better information about the predictive role of big five factors on job crafting over time. There is a shortage of previous studies that have been conducted to link the variables under study. However, previous studies have only focused on proactive personality, self-efficacy and self-regulation as the antecedents on job crafting (Tims \& Bakker, 2010). The present study found that Conscientiousness and Agreeableness predicted job crafting behaviours, but the attributes of these factors are not congruent with job crafting behaviours. Also, the study found that Extraversion was a nonsignificant predictor of job crafting behaviours, but the attributes of extraverted individuals are more congruent with job crafting behaviours. The present study therefore needs to be replicated by future researchers to confirm its research findings. Macro-scale studies should be conducted in multisites to allow the findings to be generalised beyond the population of the present study.

\section{Conclusion}

Notwithstanding the weakness of the research design, the findings of the present study contribute new ideas into the theoretical knowledge of job crafting. It also provides empirical evidence in support of big five factors as the predictors of job crafting, as the previous researchers have highlighted that they are associated with many job behaviours (Ozer \& Benet-Martinez, 2006). This therefore further supports a proposition by a person-job fit theory that the less the congruence between employees' attributes of Conscientiousness, Extraversion, Agreeableness, Openness to experience and Neuroticism and those required in their jobs, the greater the propensities for them to engage themselves in job crafting behaviours in their organisations to achieve a person-job fit (Greenberg, 2011). It is also expected that the present study will stimulate more researches on the predictive validity of big five personalities on job crafting propensities.

\section{Acknowledgements}

This research was funded by the Govan Mbeki Research and Development Centre (University of Fort Hare, South Africa).

\section{Competing interests}

The authors declare that they have no financial or personal relationships which may have inappropriately influenced them in writing this article.

\section{Authors' contributions}

C.B. was the leader of the project. As such, he was responsible for designing the research methodology, analysing the research data, writing the subject content of the paper, and editing the paper with regards to content, structure, and language. N.N. was responsible for data collection and its procedures that needed to be followed. She also edited the referencing of the paper. Furthermore, she was also responsible for editing editor's final comments.

\section{References}

Bakker, A.B., \& Demerouti, E. (2007). The job demands-resources model: State of the art. Journal of Managerial Psychology, 22, 309-328.

Bell, C., \& Murugan, C. (2013). The relationship between conscientiousness, extraversion and leadership effectiveness among local government managers in Eastern Cape, South Africa. African Journal of Business Management, 7 4386-4397.

Bell, C., Murugan, C., \& Nel, P. (2014). The impact of participative and directive leadership on organisational culture: An organisational development perspective. Mediterranean Journal of Social Science, 5, 2039-2117.

Benet-Martinez, V., \& John, O.P. (1998). Los Cinco Grandes across cultures and ethnic groups: Multitrait-multimethod analyses of the Big Five in Spanish and English. Journal of Personality and Social Psychology, 75, 729-750.

Berg, J.M., Dutton, J.E., \& Wrzesniewski, A. (2007). What is job crafting and why does it matter? Theory-to-practice briefing. Regents of the University of Michigan, Ross School of Business: Michigan.

Berg, J.M., Wrzesniewsk, A., \& Dutton, J.E. (2010). Perceiving and responding to challenges in job crafting at different ranks: When proactivity requires adaptivity. Journal of Organizational Behaviour, 31, 158-186.

Bono, J.E., \& Judge, T.A. (2004). Personality and transformational and transactional leadership: A meta-analysis. Journal of Applied Psychology, 89(5), 901-910.

Bosnjak, M., Galesic, M., \& Tuten, T.L. (2007). Personality determinants of online shopping: Explaining online purchase intentions using a hierarchal approach. Journal of Business Research, 60(6), 597-605.

Costa, P.T., \& McCrae, R.R. (1992). The five-factor model of personality and its relevance to personality disorders. Journal of Personality Disorders, 6, 343-359.

Dingman, J.M. (1990). Personality structure: Emergence of the five-factor model. Annual Review of Psychology, 41(4), 17-40.

Durheim, K., \& Painter, D. (2006). Collecting quantitative data. In M. Terre Blanche, K. Durheim, \& D. Painter (Eds.), Research methods in practice: Applied methods for the social sciences, (pp. 132-159). Cape Town: UCT Press.

Fincham, R., \& Rhodes, P. (2005). Principles of organisational behaviour. (5th edn.). New York: Oxford University Press.

Funder, D.C. (2001). Personality. Annual Review of Psychology, 52, 197-221.

Greenberg, J. (2011). Behaviour in organisations: Understanding and managing the human side of work. England: Pearson Education International.

Gregory, R.J. (2007). Psychological testing: History, principles, and applications (5th edn.). Boston, MA: Pearson International Edition.

Hair, J.F., Wolfinbarger, M., Ortinau, D.J., \& Bush, R.P. (2008). Essentials of marketing research. New York: McGraw-Hill Companies, Inc.

Huysamen, G.K. (1994). Methodology for the social and behavioural sciences. Pretoria: Southern Book Publishers.

John, O.P., \& Srivastava, S. (1999). The big five trait taxonomy: History measurement and theoretical perspectives. In L.A. Pervin, \& O.P. John (Eds.), Handbook of personality: Theory and research (2nd ed., pp. 102-138). New York: Guilford personal
Press.

John, O.P., Donahue, E.M., \& Kentle, R.L. (1991). The big five inventory-versions $4 a$ and 54 Berkeley. Berkeley, CA: Institute of Personality and Social Research, University of California.

Komarraju, M., Karau, S.J., Schmeck, R.R., \& Avdic, A. (2011). The big five personality traits, learning styles, and academic achievement. Personality and Individual Differences, 51, 472-477.

LaRose, R., \& Eastin, M.S. (2002). Is online buying out of control? electronic commerce and consumer self-regulation. Journal of Broadcasting and Electronic Media, 46(4), 549-564.

Larsen, R.J., \& Buss, D.M. (2010). Personality psychology: Domains of knowledge about human nature. (4th edn.). New York: McGraw-Hill.

Lounsbury, J., Loveland, J., Sundstrom, E., Gibson, L., Drost, A., \& Hamrick, F.L. (2003) Career satisfaction. Journal of Career Assessment, 11(3), 287-307.

Matzler, K., Faullant, R., Renzl, B., \& Leiter, V. (2005). The relationship between personality traits (extraversion and neuroticism), emotions and customer selfsatisfaction. Innovative Marketing, 1(2), 9-32.

McCrae, R.R., \& Costa, P.T. (2003). Personality in adulthood: A five-factor theory perspective (2nd edn.). New York: Guilford Press. 
Mehmetoglu, M. (2012). Personality effects on experiential consumption. Personality and Individual Differences, 52, 94-99.

Mondak, J.J. (2010). Personality and the foundations of political behaviour. New York: Cambridge University Press.

Nunnally, J.C., \& Bernstein, J. (1994). Psychometric theory. New York, NY: McGraw Hill.

Ozer, D.J., \& Benet-Martinez, V. (2006). Personality and the prediction of consequential outcomes. Annual Review of Psychology, 57, 401-421.

Raosoft, Inc. (2004). Raosoft sample size calculator. Retrieved November 22, 2013, from http://www.raosoft.com/samplesize.html

Roberts, B.W., Kuncel, N.R., Shiner, R., Caspi, A., \& Goldberg, L.R. (2007). The power of personality: The comparative validity of personality traits, socioeconomic status, and cognitive ability for predicting important life outcomes. Association for Psychological Science, 4(2), 313-345.

Schaufeli, W.B. (2013). What is engagement? In C. Truss, K. Alfes, R. Delbridge, A. Shantz, \& E. Soane (Eds.), Employee engagement in theory and practice. (pp. 1-37). London: Routledge.

Schiffman, L.G., \& Kanuk, L.L. (2007). Consumer behaviour. New Jersey: Pearson Prentice Hall.

Steyn, H.S. (2002). Practically significant relationships between two variables. SA Journal of Industrial Psychology, 28(3), 10-15.
Tims, M., \& Bakker, A.B. (2010). Job crafting: Towards a new model of individual job redesign. SA Journal of Industrial Psychology, 36(2), 1-9.

Tims, M., Bakker, A.B., \& Derks, D. (2012). Development and validation of the job crafting scale. Journal of Vocational Behaviour, 80, 173-186.

Tims, M., Bakker, A.B., \& Derks, D. (2013). The impact of job crafting on job demands, job resources, and well-being. Journal of Occupational Health Psychology, 18(2), 230-240.

Tims, M., Bakker, A.B., \& Derks, D. (2014). Daily job crafting and the self-efficacyperformance relationship. Journal of Managerial Psychology, 5(29), 490-507.

Vreugdenhil, H., Kooij, T.A.M., \& Van Veldhoven, M.J.P.M. (2012). Do older employees use task crafting in order to reduce the perceived misfit with their job: The influence of future time perspective and proactive personality-a diary study? Master thesis Human Resource Studies, Universiteit Van Tilburg.

Welman, C., Kruger, F., \& Mitchell, B. (2005). Research methodology. (3th edn.) Oxford: Southern Africa.

Wrzesniewski, A., LoBuglio, N., Dutton, J.E., \& Berg, J.M. (2013). Job crafting and cultivating positive meaning and identity in work. Advances in Positive Organizational Psychology, 1, 281-302. 